\title{
TIM-3 as a novel therapeutic target for eradicating acute myelogenous leukemia stem cells
}

\author{
Yoshikane Kikushige $\cdot$ Toshihiro Miyamoto
}

Received: 24 July 2013/Revised: 5 September 2013/Accepted: 5 September 2013/Published online: 18 September 2013

(c) The Japanese Society of Hematology 2013

\begin{abstract}
Acute myelogenous leukemia (AML) originates from self-renewing leukemic stem cells (LSCs), which represent the ultimate therapeutic target for AML. Recent studies have identified several AML LSC-specific surface antigens as candidate targets of therapeutic molecules. T cell immunoglobulin mucin-3 (TIM-3) is expressed on LSCs in most types of AML, with the exception of acute promyelocytic leukemia, but not on normal hematopoietic stem cells (HSCs). In xenograft models reconstituted with human AML LSCs or HSCs, an anti-human TIM-3 mouse IgG2a antibody with cytotoxic activities eradicates AML LSCs in vivo, but does not affect normal human hematopoiesis. Thus, TIM-3 is a promising therapeutic target for the eradication of AML LSCs.
\end{abstract}

Keywords Acute myelogeneous leukemia .

Leukemic stem cell · TIM-3

\section{Introduction}

Human hematopoietic stem cells (HSCs) reside within the $\mathrm{CD} 34^{+} \mathrm{CD} 38^{-}$cell fraction of bone marrow. HSCs have the potential to self-renew and differentiate into multilineage mature hematopoietic cells and thereby maintain normal hematopoiesis. By virtue of their organization into such a hierarchical system, HSCs are able to regulate

Y. Kikushige $\cdot$ T. Miyamoto $(\square)$

Department of Medicine and Biosystemic Sciences, Kyushu

University Graduate School of Medicine, 3-1-1 Maidashi,

Higashi-Ku, Fukuoka 812-8582, Japan

e-mail: toshmiya@intmed1.med.kyushu-u.ac.jp

Y. Kikushige

Japan Society for the Promotion of Science, Tokyo, Japan dynamic homeostasis of hematopoiesis. Similarly, in acute myelogenous leukemia (AML), a small number of leukemic cells, called leukemic stem cells (LSCs) or leukemiainitiating cells, are found within the same $\mathrm{CD} 34^{+} \mathrm{CD} 38^{-}$ cell fraction. LSCs self-renew and give rise to clonogenic leukemic cells, whereas non-LSCs lack the potential to self-renew or maintain leukemia, thus AML is also organized as a hierarchy, which originates from LSCs [1-3]. The concept of LSCs has been proposed based on the finding in the 1980s that only a limited fraction of AML cells can give rise to blast colonies in vitro. In 1994, Dick et al. showed that the $\mathrm{CD} 34^{+} \mathrm{CD} 38^{-}$AML leukemic cells, but not other AML cells, including $\mathrm{CD} 34^{+} \mathrm{CD} 38^{+}$and CD34- leukemic cells, can reconstitute human AML in immunodeficient mice, providing direct evidence for the existence of LSCs [1]. Although recent studies have suggested that LSCs in some types of AML may be present within the $\mathrm{CD} 34^{+} \mathrm{CD} 38^{+}$fraction [4] or the $\mathrm{CD} 34^{-}$leukemic cell fraction as well $[5,6]$, the $\mathrm{CD} 34^{+} \mathrm{CD} 38^{-}$population concentrates the LSCs in a vast majority of cases [7]. The $\mathrm{CD} 34^{+} \mathrm{CD} 38^{-}$phenotype is identical to that of very primitive human HSCs with long-term reconstitution activity $[8,9]$ and multipotent progenitor cells, suggesting the possibility that LSCs originate from these very primitive HSCs or progenitor cells [10].

In the clinic, conventional chemotherapy currently achieves complete remission in $\sim 90 \%$ of AML cases [11, 12]. However, a considerable fraction $(\sim 60 \%)$ of AML patients eventually relapse after intensive chemotherapies. The recurrence of AML in these patients may be caused by re-growth of surviving LSCs. Thus, LSCs should be the ultimate therapeutic target if we are to achieve a cure for AML. To selectively kill AML LSCs while sparing normal HSCs, one of the most practical approaches is to target AML LSC-specific surface molecules or molecules 
required for LSC function. To achieve such specificity, the target molecule should be expressed on LSCs at a high level, but not on normal HSCs [13]. It does not matter whether the molecule is expressed in normal blood cells or normal progenitor cells, because if physiologic HSCs are spared, they are able to replenish all mature blood cells after the conclusion of treatment.

Recently, two groups have identified $\mathrm{T}$ cell immunoglobulin mucin-3 (TIM-3) as a surface molecule expressed in LSCs of most AML types [14, 15]. TIM-3 is a promising therapeutic molecule for the targeting of LSCs while sparing normal residual HSCs [14]. Furthermore, a recent study has succeeded in the prospective separation of LSCs from residual HSCs in de novo AML patients by TIM-3 expression, allowing us to clarify the clonal relationship between LSCs and HSCs in the same patient [16]. In this review, we summarize recent progress in studies of TIM-3 and discuss the potential utility of TIM-3 for eradicating AML LSCs while leaving normal HSCs unaffected.

TIM-3 in normal hematopoiesis

TIM-3 was first identified as a surface molecule expressed in interferon (IFN)- $\gamma$-producing $\mathrm{CD}^{+}$Th1 cells and in $\mathrm{CD}^{+} \mathrm{T}$ cytotoxic type 1 ( $\left.\mathrm{Tc} 1\right)$ cells [17] in murine hematopoiesis. TIM-3, a type 1 cell-surface glycoprotein, has a structure that includes an $\mathrm{N}$-terminal immunoglobulin variable domain followed by a mucin domain, a transmembrane domain and a cytoplasmic tail. Figure 1 shows the structure of TIM-3 and its ligands. TIM-3 plays an

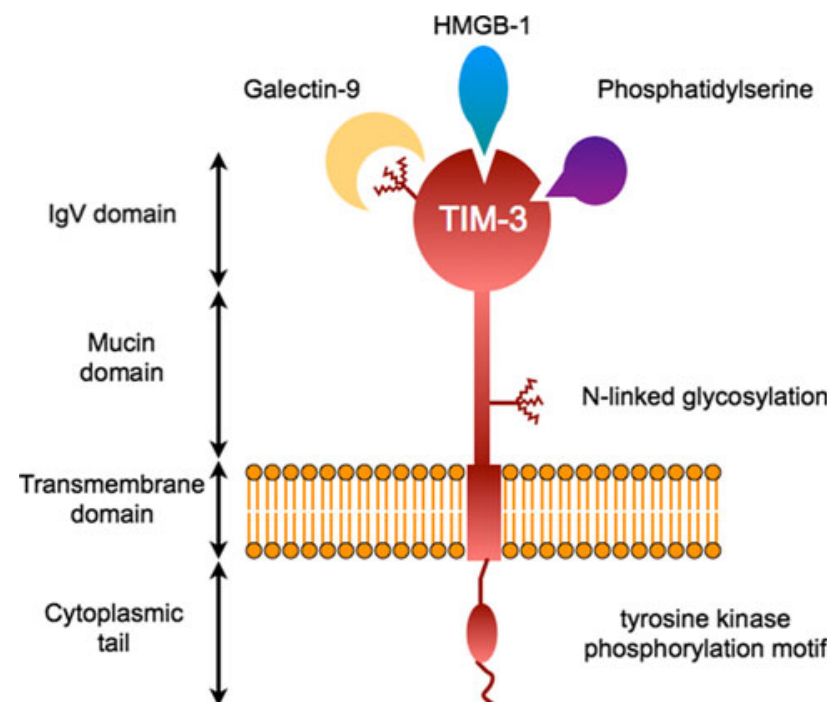

Fig. 1 Structure of TIM-3 molecule and its ligands. TIM-3 is a type 1 cell-surface glycoprotein and has a structure that includes an $\mathrm{N}$-terminal immunoglobulin variable domain followed by a mucin domain, a transmembrane domain and a cytoplasmic tail with highly conserved six tyrosine residues and an $\mathrm{SH} 2$ binding motif. Galectin-9, HMGB1 and PS have been identified as ligands of TIM-3 important role in regulating Th1-dependent immune responses and in inducing immune tolerance [17-19]. In lymphocytes, galectin-9, an S-type lectin, has been reported as a TIM-3 ligand. Galectin-9 has two distinct carbohydrate recognition domains and can bind to carbohydrate chains on the TIM-3 IgV domain. TIM-3 has highly conserved six tyrosine residues and an Src homology 2(SH2) binding motif in its cytoplasmic tail, and stimulation of TIM-3 by galectin- 9 results in increased phosphorylation of tyrosine residues in T cells [20]. Engagement of TIM-3 by galectin-9 induces apoptosis of Th1 cells and inhibits their IFN- $\gamma$ production [21]. Thus, TIM-3 is considered to be a negative regulator of Th1- and Tc1-driven immune responses.

Another aspect of TIM-3 expression in the T cell lineage is as a marker of "exhausted" $\mathrm{CD} 8^{+} \mathrm{T}$ cells. Exhausted T cells show impaired proliferation potential and effector function in response to antigen stimulation. Such exhausted $\mathrm{T}$ cells express the inhibitory molecule programmed cell death 1 (PD-1) on their surface, and $\mathrm{T}$ cell function can be partially restored by blocking the interaction between PD-1 and PD-1 ligand in mice [22]. In addition to PD-1 expression, recent studies have shown that TIM-3 expression also marks exhausted $\mathrm{CD}^{+} \mathrm{T}$ cells in patients with chronic viral infections, including human immunodeficiency virus (HIV) [23], hepatitis B virus [24] and hepatitis $\mathrm{C}$ virus (HCV) [25]. Blockade of both TIM-3 and PD-1 pathways can restore $\mathrm{T}$ cell proliferation and effector potential, suggesting that both TIM-3 and PD-1 pathways play a major role in $\mathrm{CD}^{+} \mathrm{T}$ cell exhaustion [26].

TIM-3 also plays a major role in innate immunity, by modulating immune reaction pathways. Among innate immune cells, NK cells and some kinds of myeloid cells, including monocytes/macrophages, dendritic cells and mast cells, express TIM-3 in both humans and mouse. In NK cells, TIM-3 is shown to be an inducible surface receptor on activation $[27,28]$, but its function remains controversial. Gleason et al. [27] reported TIM-3 as a human NK cell co-receptor to enhance IFN- $\gamma$ production, whereas Ndhlovu et.al reported the inhibition of NK cellmediated cytotoxicity by TIM-3 cross-linking [28]. Further studies are necessary to clarify the precise function of TIM3 in NK cells. In the myeloid lineage, TIM-3 is expressed in monocytes/macrophages, dendritic cells (DCs) and mast cells [29-32]. TIM-3 expressed on monocytes or DCs synergizes with Toll-like receptors to promote tumor necrosis factor- $\alpha$ (TNF- $\alpha$ ) secretion and enhances inflammatory responses [29]. In addition, TIM-3 on macrophages and DCs recognizes phosphatidylserine (PS) in apoptotic cells through its IgV domain. Binding of PS to TIM-3 does not interfere with that of galectin-9 to TIM-3, as the binding sites of these molecules are located on opposite sides of the IgV domain. In TIM-3-expressing DCs, 
recognition of PS by TIM-3 induced enhancement of phagocytosis of apoptotic cells and cross-presentation of apoptotic cell-associated antigen to $\mathrm{CD}^{+} \mathrm{T}$ cells [30]. In addition to the previously identified TIM-3 ligands, galectin-9 and PS, a recent study revealed that high mobility group box 1 (HMGB1) serves as a ligand for TIM3 in tumor-associated DCs (TADCs). TIM-3 is highly expressed in TADCs and suppresses nucleic acid-mediated innate immune response independently of galectin-9 or PS. HMGB1 has the potential to trigger the transportation of nucleic acids into endosomes in DCs. TIM-3 inhibits the recruitment of nucleic acids to endosomes by trapping HMGB1, and attenuates the innate immune response against tumor [33]. As described above, TIM-3 is expressed in various types of hematopoietic cells and seems to have lineage- or cellular context-dependent signal transduction pathways or functions [29]. Further studies will help us to understand the detailed function of TIM-3.

In steady-state human hematopoiesis, TIM-3 is expressed mainly in monocytes and a fraction of NK cells, but not in granulocytes, B cells or the vast majority of T cells [14]. In human bone marrow, $\mathrm{CD} 34^{+} \mathrm{CD} 38^{-} \mathrm{CD} 90^{+} \mathrm{Lin}^{-}$normal HSCs and the vast majority of the $\mathrm{CD} 34^{+} \mathrm{CD} 38^{+}$progenitor cells lack TIM-3 expression. Within the CD $34^{+} \mathrm{CD} 38^{+}$ progenitor fraction, human myeloid progenitors can be divided into three progenitors, including common myeloid progenitors (CMPs), granulocyte/macrophage progenitors (GMPs) and megakaryocyte/erythrocyte progenitors (MEPs), by the expression of CD123 and CD45RA [34]. Of these myeloid progenitors, TIM-3 is expressed only in a fraction GMPs, but not in CMPs and MEPs. The vast majority of purified TIM-3 ${ }^{+}$GMPs mainly give rise to colony forming unit-macrophage (CFU-M), whereas TIM$3^{-}$GMPs give rise to various types of myeloid colonies, including colony forming unit-granulocyte/macrophage (CFU-GM), colony forming unit-granulocyte (CFU-G) and CFU-M, suggesting that upregulation of TIM-3 occurs in concert with monocyte lineage commitment at the GMP stage in human [14].

\section{TIM-3 in AML}

Many studies of TIM-3 have focused on its role as an immune modulating molecule and intensively investigated in the field of immunology; however, the studies on its role or expression in hematological malignancies have been limited so far. We and another group identified TIM-3 as an AML LSC-specific surface molecule based on the transcriptome analysis between gene expression profiles of CD34 ${ }^{+} \mathrm{CD}^{-} 8^{-}$AML cells and normal HSCs (Fig. 2a). As shown in Fig. 2b, TIM-3 protein is not expressed in $\mathrm{CD} 34^{+} \mathrm{CD} 38^{-} \mathrm{CD}^{+} 0^{+} \mathrm{Lin}^{-}$normal $\mathrm{HSCs}$, but the vast majority of the $\mathrm{CD} 34^{+} \mathrm{CD} 38^{-} \mathrm{LSCs}$ as well as the
$\mathrm{CD} 34^{+} \mathrm{CD} 38^{+}$cells in most types of AML except for acute promyelocytic leukemia express TIM-3 protein at a high level $[14,15]$. Notably, it has been reported that the expression level of TIM-3 is high in AML with corebinding factor translocations or mutations in CEBPA [15].

Strikingly, the TIM- $3^{+}$population in the bone marrow contains all AML LSCs, and residual HSCs are always included in patients' TIM- $^{-}$population. To test the significance of this, TIM- $3^{+}$and TIM- $3^{-}$AML populations were transplanted into sublethally irradiated immunodeficient mice, and it was found that only TIM- $3^{+}$AML cells reconstituted human AML in mice [14]. Jan et al. [15] reported that normal human hematopoiesis is always reconstituted in the mice transplanted with CD $34^{+}$CD $38^{-}$TIM- $3^{-}$cells from AML patients, suggesting that TIM-3 may be a useful marker to separate residual HSCs from AML LSCs. Jan et al. also compared the gene mutation status of the prospectively isolated residual CD $34^{+}{ }^{+}$D $38^{-}$CD $99^{-}$TIM- ${ }^{-}$HSCs and TIM- $^{+}$AML cells in the same AML patients by exome sequencing, and found that the presence of pre-leukemic HSCs harboring identical gene mutations to those of paired AML cells, revealing the multi-step leukemogenesis from self-renewing HSCs [16]. These studies reveal that TIM-3 expression is very specific to AML and is useful in clearly distinguishing HSCs from LSCs.

Targeting AML LSCs by anti-TIM-3 killing antibodies

To utilize TIM-3 to target AML LSCs, it is critical to establish anti-human TIM-3 antibodies that can kill TIM-3expressing cells in vivo. In terms of the antibody-based treatment, the antibody-dependent cellular cytotoxicity (ADCC), as well as the complement-dependent cytotoxicity (CDC) activities is critical to eliminate target cells [35]. Additionally, recent studies have suggested that antibodydependent cellular phagocytosis (ADCP) could play an important role in killing target cells in vitro [36] and vivo [37].

An anti-TIM-3 monoclonal antibody (IgG2b) was obtained by immunizing Balb/c mice with L929 cells stably expressing human TIM-3 and soluble TIM-3 protein. In this antibody, the variable portions of the $\mathrm{VH}$ regions of the cloned hybridoma that recognize TIM-3 were grafted onto IgG2a Fc regions, because IgG2a subclass is most efficient to induce ADCC activity in mice [38, 39]. The established clone, ATIK2a, was effective in killing TIM-3-expressing cell lines via both CDC and ADCC effects [14].

The effect of ATIK2a on normal and malignant AML hematopoiesis was tested in xenograft models. NOD-SCID mice transplanted with $10^{5} \mathrm{CD}_{3} 4^{+}$cord blood cells with or without ATIK2a treatment developed nearly equal percentages of human hematopoietic cells. In mice injected 
Fig. 2 TIM-3 expression in normal HSCs and AML LSCs. a Results of gene expression analysis comparing CD $34^{+} \mathrm{CD} 38^{-}$normal HSCs and AML LSCs. Surface molecules highly expressed in LSCs are shown. b FACS analysis of TIM-3 protein expression in normal HSCs and AML LSCs. Both

$\mathrm{CD} 34^{+} \mathrm{CD} 38^{-} \mathrm{CD} 90^{-}$LSCs and $\mathrm{CD} 34^{+} \mathrm{CD} 38^{+}$AML cells express TIM-3, whereas CD $34^{+} \mathrm{CD} 38^{-} \mathrm{CD}^{-} 0^{-} \mathrm{HSCs}$ completely lack TIM-3 expression. TIM-3 expression originates within the $\mathrm{CD} 34^{+} \mathrm{CD} 38^{+}$progenitor fraction in normal human hematopoiesis. Representative FACS analysis results of TIM-3 expression are shown here

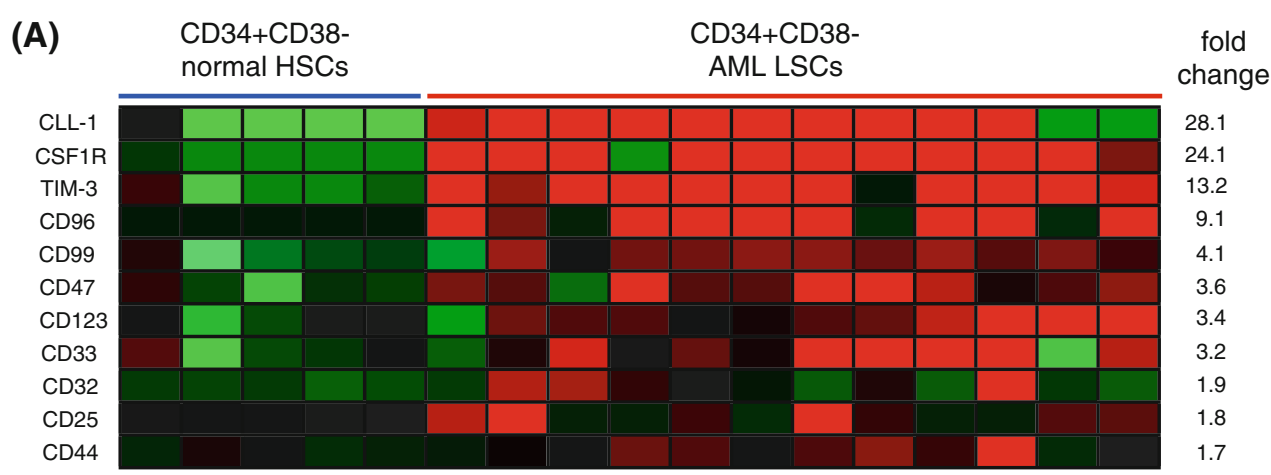

(B)

AML
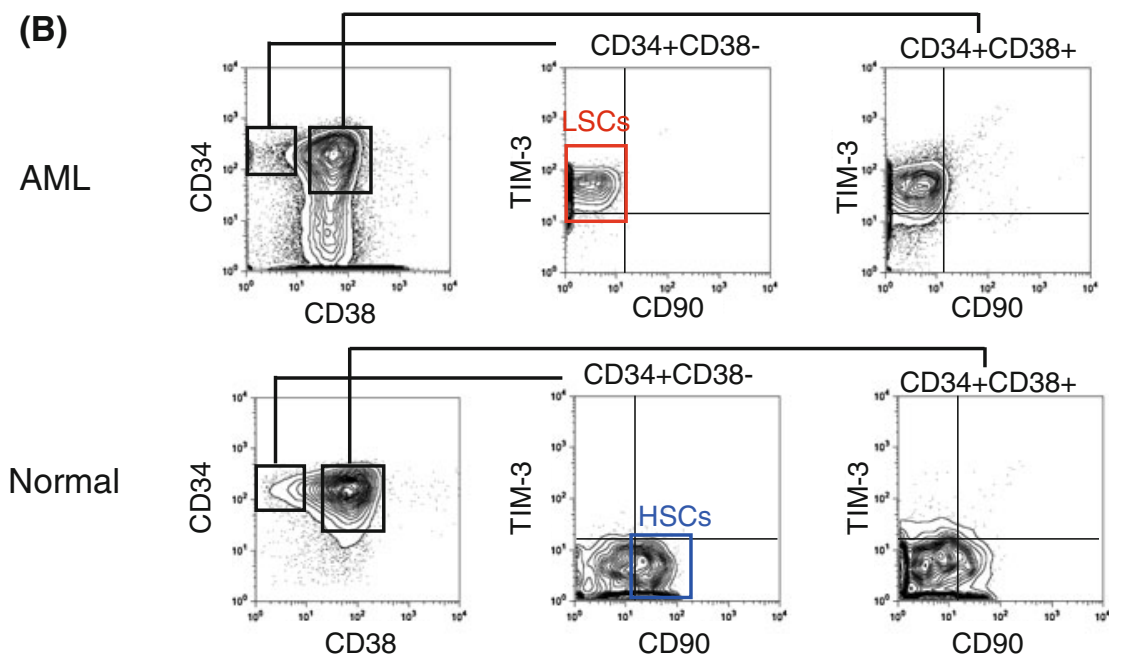

with ATIK2a, however, human $\mathrm{CD} 33^{+}{ }^{\mathrm{TIM}}-3^{+}$mature monocytes were depleted, suggesting that targeting TIM-3 does not affect development of normal hematopoiesis, killing only the normal TIM- $3^{+}$cells.

In contrast, against AML cells, ATIK2a exerted profound effects on leukemia development. In mice transplanted with human AML of M0, M1 and M4 types, ATIK2a treatment significantly reduced the human CD45 ${ }^{+}$ AML burden as well as the $\mathrm{CD} 34^{+} \mathrm{CD} 38^{-}$LSC cell numbers in vivo. Re-transplantation of the remaining AML cells in primary recipients treated with ATIK2a into the secondary recipients failed to reconstitute human AML, indicating that ATIK2a treatment successfully eradicated functional LSCs in primary recipients. These data suggest that eliminating AML LSCs by using anti-TIM-3 killing antibodies is a practical approach to cure human AML.

\section{Perspective}

To target surface antigens on AML LSCs, it is critical to specifically kill LSCs sparing normal HSCs with high sensitivity. TIM-3 has several advantages over other candidate markers. First, TIM-3 protein is not detectable in normal HSCs, or in other myelo-erythroid or lymphoid progenitors, although TIM-3 is upregulated in monocyte lineage committed progenitors. Second, TIM-3 marks all functional LSCs that can reconstitute human AML in immunodeficient mice in the majority of M0, M1, M2 and M4 AML cases, and its expression level is sufficient to eradicate LSCs by antibody-based treatment. The expression level of other candidate molecules, including CD25 [40], CD32 [40], CD44 [41] and CD47 [42] in LSCs, was only two- to threefold higher at the mRNA level as compared to normal HSCs in our own transcriptome analysis, and in some AML cases, LSCs did not express these molecules. CD33 and CD123 [43] proteins are expressed at a considerably high level in normal HSCs and myeloid progenitors including CMPs and GMPs [44], suggesting that targeting these molecules should harm normal hematopoiesis. In fact, prolonged cytopenia has been observed in AML patients treated with gemtuzumab [45], a recombinant humanized anti-CD33 monoclonal antibody conjugated with the cytotoxic antibiotic calicheamicin. In contrast, CLL-1 [46], CSF1R [47], CD96 [48] and CD99 [16] are all specifically expressed in LSCs. CLL-1 is a transmembrane glycoprotein [49]. The proportion of CLL1-expressing $\mathrm{CD} 34^{+} \mathrm{CD} 38^{-}$AML cells is highly diversified in cases [46]. CD96 is a member of the Ig gene superfamily. CD96 is expressed on activated T cells [50]. Of note, like in the case of TIM-3, CD96 ${ }^{+}$but not CD96 $6^{-}$ 
AML cells efficiently reconstituted AML in the immunodeficient mice [48], suggesting that CD96 can mark all functional AML LSCs. The expression level of CD96 protein is also high enough to clearly distinguish AML LSCs from normal HSCs. The sensitivity of TIM-3 is likely to be the highest among these molecules, at least for AML M0, M1, M2 and M4.

It is important to understand the function of these therapeutic target molecules on the development of AML. For example, it has been shown that anti-CD44 monoclonal antibodies reduce the leukemic burden and block secondary engraftment in an NOD-SCID model [41]. This effect on LSCs was mediated in part by the disruption of LSCniche interactions [41]. Anti-CD47 antibodies can block LSC reconstitution in an NOD-SCID model [42], and this might be due to the activation of phagocytosis by macrophages through inhibition of interaction of CD47 with SIRPA [51]. Since the pathway for eradication of LSCs by anti-CD44 or anti-CD47 treatment is different from that by anti-TIM3 antibodies, the combination of these antibodies might be critical for future treatments targeting AML LSCs. Unlike the cases in CD44 and CD47, the function of TIM-3 molecule in AML is still largely unknown. TIM-3 is expressed in the various types of hematopoietic cells and seems to have lineage- or cellular context-dependent signal transduction pathways or functions. TIM-3 expression and functions in hematopoietic cells are summarized in Fig. 3.

Recent studies reported the ectopic expression of TIM-3 in lineages other than hematopoietic cells, particularly in primary cancer cells, including melanoma [52], non-small cell lung cancer [53], cervical cancer [54] and liposarcoma [55]. Importantly, patients with TIM-3 positive cancer cells had a significantly shorter survival time than those with TIM-3 negative cancer cells in non-small cell lung cancer

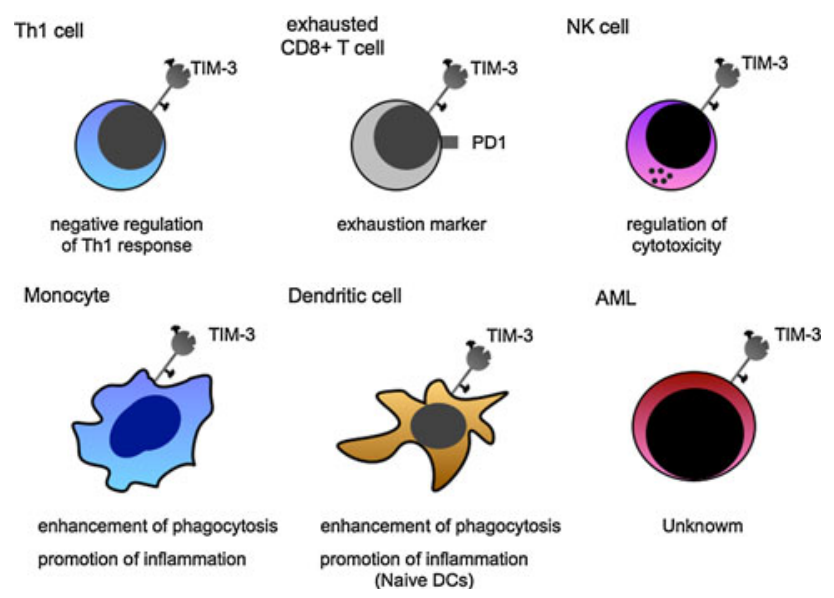

Fig. 3 TIM-3 expression and functions in hematopoietic cells. TIM-3 is expressed in Th1 cells, exhausted $\mathrm{CD}^{+} \mathrm{T}$ cells, NK cells, monocytes and dendritic cells in normal hematopoiesis. Functions of TIM-3 differ by cell type and context
[53] and cervical cancer [54]. TIM-3 expression in these various types of malignant cells raises the possibility of tumorigenic function of TIM-3. Further studies will help us to find out the TIM-3 function in malignant cells.

\section{Conclusion}

TIM-3 plays pivotal and diverse roles in modulating immune reaction. We identified TIM-3 as a specific surface molecule expressed in AML LSCs through transcriptome analysis of normal HSCs and AML LSCs. TIM-3 expression can distinguish AML LSCs from normal HSCs, indicating that targeting TIM-3 may be a useful therapeutic approach. We have developed antibody-based therapeutic xenograft model of primary AML cells, and shown that targeting TIM-3 by cytotoxic monoclonal antibodies kills functional LSCs in vivo. Thus, TIM-3 is a promising therapeutic target for the eradication of AML LSCs.

\section{Conflict of interest None.}

\section{References}

1. Lapidot T, Sirard C, Vormoor J, Murdoch B, Hoang T, CaceresCortes $\mathrm{J}$, et al. A cell initiating human acute myeloid leukaemia after transplantation into SCID mice. Nature. 1994;367(6464): $645-8$.

2. Bonnet D, Dick JE. Human acute myeloid leukemia is organized as a hierarchy that originates from a primitive hematopoietic cell. Nat Med. 1997;3(7):730-7.

3. Hope KJ, Jin L, Dick JE. Acute myeloid leukemia originates from a hierarchy of leukemic stem cell classes that differ in selfrenewal capacity. Nat Immunol. 2004;5(7):738-43.

4. Taussig DC, Miraki-Moud F, Anjos-Afonso F, Pearce DJ, Allen $\mathrm{K}$, Ridler C, et al. Anti-CD38 antibody-mediated clearance of human repopulating cells masks the heterogeneity of leukemiainitiating cells. Blood. 2008;112(3):568-75.

5. Martelli MP, Pettirossi V, Thiede C, Bonifacio E, Mezzasoma F, Cecchini D, et al. CD34+ cells from AML with mutated NPM1 harbor cytoplasmic mutated nucleophosmin and generate leukemia in immunocompromised mice. Blood. 2010;116(19): 3907-22.

6. Taussig DC, Vargaftig J, Miraki-Moud F, Griessinger E, Sharrock K, Luke T, et al. Leukemia-initiating cells from some acute myeloid leukemia patients with mutated nucleophosmin reside in the CD34(-) fraction. Blood. 2010;115(10):1976-84.

7. Ishikawa F, Yoshida S, Saito Y, Hijikata A, Kitamura H, Tanaka $\mathrm{S}$, et al. Chemotherapy-resistant human AML stem cells home to and engraft within the bone-marrow endosteal region. Nat Biotechnol. 2007;25(11):1315-21.

8. Bhatia M, Wang JC, Kapp U, Bonnet D, Dick JE. Purification of primitive human hematopoietic cells capable of repopulating immune-deficient mice. Proc Natl Acad Sci USA. 1997;94(10): 5320-5.

9. Ishikawa F, Yasukawa M, Lyons B, Yoshida S, Miyamoto T, Yoshimoto G, et al. Development of functional human blood and immune systems in NOD/SCID/IL2 receptor gamma chain(null) mice. Blood. 2005;106(5):1565-73. 
10. Goardon N, Marchi E, Atzberger A, Quek L, Schuh A, Soneji S, et al. Coexistence of LMPP-like and GMP-like leukemia stem cells in acute myeloid leukemia. Cancer Cell. 2011;19(1):138-52.

11. Miyawaki S. Clinical studies of acute myeloid leukemia in the Japan Adult Leukemia Study Group. Int J Hematol. 2012;96(2): 171-7.

12. Stein EM, Tallman MS. Remission induction in acute myeloid leukemia. Int J Hematol. 2012;96(2):164-70.

13. Krause DS, Van Etten RA. Right on target: eradicating leukemic stem cells. Trends Mol Med. 2007;13(11):470-81.

14. Kikushige Y, Shima T, Takayanagi S, Urata S, Miyamoto T, Iwasaki H, et al. TIM-3 is a promising target to selectively kill acute myeloid leukemia stem cells. Cell Stem Cell. 2010;7(6): 708-17.

15. Jan M, Chao MP, Cha AC, Alizadeh AA, Gentles AJ, Weissman IL, et al. Prospective separation of normal and leukemic stem cells based on differential expression of TIM3, a human acute myeloid leukemia stem cell marker. Proc Natl Acad Sci USA. 2011;108(12):5009-14.

16. Jan M, Snyder TM, Corces-Zimmerman MR, Vyas P, Weissman IL, Quake SR, et al. Clonal evolution of preleukemic hematopoietic stem cells precedes human acute myeloid leukemia. Sci Transl Med. 2012;4(149):149ra18.

17. Monney L, Sabatos CA, Gaglia JL, Ryu A, Waldner H, Chernova $\mathrm{T}$, et al. Th1-specific cell surface protein Tim-3 regulates macrophage activation and severity of an autoimmune disease. Nature. 2002;415(6871):536-41.

18. Sanchez-Fueyo A, Tian J, Picarella D, Domenig C, Zheng XX, Sabatos CA, et al. Tim-3 inhibits T helper type 1-mediated autoand alloimmune responses and promotes immunological tolerance. Nat Immunol. 2003;4(11):1093-101.

19. Sabatos CA, Chakravarti S, Cha E, Schubart A, Sanchez-Fueyo A, Zheng XX, et al. Interaction of Tim-3 and Tim-3 ligand regulates $\mathrm{T}$ helper type 1 responses and induction of peripheral tolerance. Nat Immunol. 2003;4(11):1102-10.

20. van de Weyer PS, Muehlfeit M, Klose C, Bonventre JV, Walz G, Kuehn EW. A highly conserved tyrosine of Tim-3 is phosphorylated upon stimulation by its ligand galectin-9. Biochem Biophys Res Commun. 2006;351(2):571-6.

21. Zhu C, Anderson AC, Schubart A, Xiong H, Imitola J, Khoury SJ, et al. The Tim-3 ligand galectin- 9 negatively regulates $\mathrm{T}$ helper type 1 immunity. Nat Immunol. 2005;6(12):1245-52.

22. Barber DL, Wherry EJ, Masopust D, Zhu B, Allison JP, Sharpe $\mathrm{AH}$, et al. Restoring function in exhausted CD8 T cells during chronic viral infection. Nature. 2006;439(7077):682-7.

23. Jones RB, Ndhlovu LC, Barbour JD, Sheth PM, Jha AR, Long BR, et al. Tim-3 expression defines a novel population of dysfunctional $\mathrm{T}$ cells with highly elevated frequencies in progressive HIV-1 infection. J Exp Med. 2008;205(12):2763-79.

24. Wu W, Shi Y, Li S, Zhang Y, Liu Y, Wu Y, et al. Blockade of Tim-3 signaling restores the virus-specific CD8(+) T-cell response in patients with chronic hepatitis B. Eur J Immunol. 2012;42(5):1180-91.

25. Golden-Mason L, Palmer BE, Kassam N, Townshend-Bulson L, Livingston $\mathrm{S}$, McMahon $\mathrm{BJ}$, et al. Negative immune regulator Tim-3 is overexpressed on $\mathrm{T}$ cells in hepatitis $\mathrm{C}$ virus infection and its blockade rescues dysfunctional CD4+ and CD8+ T cells. J Virol. 2009;83(18):9122-30.

26. Sakuishi K, Apetoh L, Sullivan JM, Blazar BR, Kuchroo VK, Anderson AC. Targeting Tim-3 and PD-1 pathways to reverse T cell exhaustion and restore anti-tumor immunity. J Exp Med. 2010;207(10):2187-94.

27. Gleason MK, Lenvik TR, McCullar V, Felices M, O’Brien MS, Cooley SA, et al. Tim-3 is an inducible human natural killer cell receptor that enhances interferon gamma production in response to galectin-9. Blood. 2012;119(13):3064-72.
28. Ndhlovu LC, Lopez-Verges S, Barbour JD, Jones RB, Jha AR, Long BR, et al. Tim-3 marks human natural killer cell maturation and suppresses cell-mediated cytotoxicity. Blood. 2012;119(16): 3734-43.

29. Anderson AC, Anderson DE, Bregoli L, Hastings WD, Kassam $\mathrm{N}$, Lei C, et al. Promotion of tissue inflammation by the immune receptor Tim-3 expressed on innate immune cells. Science. 2007;318(5853):1141-3.

30. Nakayama M, Akiba H, Takeda K, Kojima Y, Hashiguchi M, Azuma M, et al. Tim-3 mediates phagocytosis of apoptotic cells and cross-presentation. Blood. 2009;113(16):3821-30.

31. Nakae S, Iikura M, Suto H, Akiba H, Umetsu DT, Dekruyff RH, et al. TIM-1 and TIM- 3 enhancement of Th2 cytokine production by mast cells. Blood. 2007;110(7):2565-8.

32. Dekruyff RH, Bu X, Ballesteros A, Santiago C, Chim YL, Lee $\mathrm{HH}$, et al. $\mathrm{T}$ cell/transmembrane, $\mathrm{Ig}$, and mucin-3 allelic variants differentially recognize phosphatidylserine and mediate phagocytosis of apoptotic cells. J Immunol. 2010;184(4):1918-30.

33. Chiba S, Baghdadi M, Akiba H, Yoshiyama H, Kinoshita I, Dosaka-Akita $\mathrm{H}$, et al. Tumor-infiltrating DCs suppress nucleic acid-mediated innate immune responses through interactions between the receptor TIM-3 and the alarmin HMGB1. Nat Immunol. 2012;13(9):832-42.

34. Manz MG, Miyamoto T, Akashi K, Weissman IL. Prospective isolation of human clonogenic common myeloid progenitors. Proc Natl Acad Sci USA. 2002;99(18):11872-7.

35. Nimmerjahn F, Ravetch JV. Antibodies, Fc receptors and cancer. Curr Opin Immunol. 2007;19(2):239-45.

36. Manches O, Lui G, Chaperot L, Gressin R, Molens JP, Jacob MC, et al. In vitro mechanisms of action of rituximab on primary nonHodgkin lymphomas. Blood. 2003;101(3):949-54.

37. Oflazoglu E, Stone IJ, Brown L, Gordon KA, van Rooijen N, Jonas $\mathrm{M}$, et al. Macrophages and Fc-receptor interactions contribute to the antitumour activities of the anti-CD40 antibody SGN-40. Br J Cancer. 2009;100(1):113-7.

38. Nimmerjahn F, Ravetch JV. Divergent immunoglobulin g subclass activity through selective $\mathrm{Fc}$ receptor binding. Science. 2005;310(5753):1510-2.

39. Uchida J, Hamaguchi Y, Oliver JA, Ravetch JV, Poe JC, Haas $\mathrm{KM}$, et al. The innate mononuclear phagocyte network depletes $\mathrm{B}$ lymphocytes through Fc receptor-dependent mechanisms during anti-CD20 antibody immunotherapy. J Exp Med. 2004;199(12): 1659-69.

40. Saito Y, Kitamura H, Hijikata A, Tomizawa-Murasawa M, Tanaka S, Takagi S, et al. Identification of therapeutic targets for quiescent, chemotherapy-resistant human leukemia stem cells. Sci Transl Med. 2010;2(17):17ra9.

41. Jin L, Hope KJ, Zhai Q, Smadja-Joffe F, Dick JE. Targeting of CD44 eradicates human acute myeloid leukemic stem cells. Nat Med. 2006;12(10):1167-74.

42. Majeti R, Chao MP, Alizadeh AA, Pang WW, Jaiswal S, Gibbs $\mathrm{KD} \mathrm{Jr}$, et al. CD47 is an adverse prognostic factor and therapeutic antibody target on human acute myeloid leukemia stem cells. Cell. 2009;138(2):286-99.

43. Jin L, Lee EM, Ramshaw HS, Busfield SJ, Peoppl AG, Wilkinson $\mathrm{L}$, et al. Monoclonal antibody-mediated targeting of CD123, IL-3 receptor alpha chain, eliminates human acute myeloid leukemic stem cells. Cell Stem Cell. 2009;5(1):31-42.

44. Taussig DC, Pearce DJ, Simpson C, Rohatiner AZ, Lister TA, Kelly G, et al. Hematopoietic stem cells express multiple myeloid markers: implications for the origin and targeted therapy of acute myeloid leukemia. Blood. 2005;106(13):4086-92.

45. Takeshita A. Efficacy and resistance of gemtuzumab ozogamicin for acute myeloid leukemia. Int J Hematol. 2013;97(6):703-16.

46. van Rhenen A, van Dongen GA, Kelder A, Rombouts EJ, Feller $\mathrm{N}$, Moshaver B, et al. The novel AML stem cell associated 
antigen CLL-1 aids in discrimination between normal and leukemic stem cells. Blood. 2007;110(7):2659-66.

47. Aikawa Y, Katsumoto T, Zhang P, Shima H, Shino M, Terui K, et al. PU.1-mediated upregulation of CSF1R is crucial for leukemia stem cell potential induced by MOZ-TIF2. Nat Med. 2010;16(5):580-5 1p following 5.

48. Hosen N, Park CY, Tatsumi N, Oji Y, Sugiyama H, Gramatzki $\mathrm{M}$, et al. CD96 is a leukemic stem cell-specific marker in human acute myeloid leukemia. Proc Natl Acad Sci USA. 2007;104(26): 11008-13.

49. Bakker AB, van den Oudenrijn S, Bakker AQ, Feller N, van Meijer M, Bia JA, et al. C-type lectin-like molecule-1: a novel myeloid cell surface marker associated with acute myeloid leukemia. Cancer Res. 2004;64(22):8443-50.

50. Wang PL, O'Farrell S, Clayberger C, Krensky AM. Identification and molecular cloning of tactile. A novel human $\mathrm{T}$ cell activation antigen that is a member of the Ig gene superfamily. J Immunol. 1992;148(8):2600-8.
51. Takenaka K, Prasolava TK, Wang JC, Mortin-Toth SM, Khalouei $\mathrm{S}$, Gan OI, et al. Polymorphism in Sirpa modulates engraftment of human hematopoietic stem cells. Nat Immunol. 2007;8(12): 1313-23.

52. Wiener Z, Kohalmi B, Pocza P, Jeager J, Tolgyesi G, Toth S, et al. TIM-3 is expressed in melanoma cells and is upregulated in TGF-beta stimulated mast cells. J Invest Dermatol. 2007;127(4): 906-14.

53. Zhuang $X$, Zhang $X$, Xia X, Zhang C, Liang X, Gao L, et al. Ectopic expression of TIM-3 in lung cancers: a potential independent prognostic factor for patients with NSCLC. Am J Clin Pathol. 2012;137(6):978-85.

54. Cao Y, Zhou X, Huang X, Li Q, Gao L, Jiang L, et al. Tim-3 expression in cervical cancer promotes tumor metastasis. PLoS One. 2013;8(1):e53834.

55. Li H, Zhou X, Ran Q, Wang L. Parapharyngeal liposarcoma: a case report. Diagn Pathol. 2013;8:42. 